How to cite this article: Ribeiro, A. P. (2018). Para acabar de vez com a lusofonia. Lusotopie, 17(2), 220-226. https://doi.org/10.1163/1768308412341728

\title{
Para acabar de vez com a lusofonia*
}

\section{António Pinto Ribeiro}

Centro de Estudos Sociais, Coimbra

Projecto Memoirs, filhos do império e pós-memórias europeias

\section{Resumo}

O termo lusofonia tem sido aceite e até proclamado como estratégia de entendimento entre as comunidades de Portugal e dos PALOPs como um facto inquestionável. Para que tal aconteça o termo tem sido mascarado como sendo uma emanação do português como língua oficial destes países. No entanto isto é uma falácia. A sustentar este termo está a ideia de que todas as culturas dos PALOPs se inspiram na matriz de uma cultura portuguesa essencialista associada ao luso-tropicalismo teorizado por Gilberto Freyre. Conclui-se que a lusofonia na verdade é uma forma de neo-colonialismo de Portugal ao qual não são indiferentes os vários interesses dos negócios entre as elites destes países.

\section{Palavras-chaves}

Lusofonia; PALOPs; neo-colonialismo; português; comércio

\section{For an End to Lusophony}

\section{Abstract}

The term lusophony has unquestionably been accepted and even proclaimed as a strategy of understanding between the communities of Portugal and the PALOPs. During this process, the term itself has been masked as an emanation of Portuguese

* O presente texto é uma versão actualizada do texto publicado no jornal Público a 18 de Janeiro de 2013. Artigo escrito não conforme o actual acordo ortográfico. 
being the official language of these countries. However this is a fallacy. Supporting this term is the idea that all cultures of the PALOPs are inspired by the matrix of a Portuguese essencialist culture associated with Luso-tropicalism theorized by Gilberto Freyre. It is concluded that lusophony is in fact a form of neo-colonialism of Portugal to which the various business interests between the elites of these countries are not indifferent.

\section{Keywords}

Lusophony; PALOPs; Neo-colonialism; Portuguese; Business

\section{Pour en finir avec la lusophonie}

\section{Résumé}

Le terme lusophonie a été accepté et même proclamé de manière non questionnable comme stratégie d'entente entre les communautés du Portugal et des PALOP. Pour qu'il en soit ainsi, le terme a été masqué en tant qu'émanation du portugais langue officielle de ces pays. Cependant, ceci est une tromperie. Au fondement de ce vocable se trouve l'idée que toutes les cultures des PALOP s'inspirent de la matrice d'une culture portugaise essentialisée, associée au luso-tropicalisme théorisé par Gilberto Freyre. On peut en conclure que la lusophonie est en vérité une forme de néocolonialisme du Portugal, auquel ne sont pas indifférents les divers intérêts d'affaires entre les élites de ces pays.

\section{Mots-clefs}

Lusophonie; PALOP; nécocolonialisme; portugais; commerce

Lusofonia é um conceito vago, demasiado vago. Este conceito remete para uma versão kitsch de uma boa relação de Portugal com os países que foram suas colónias, hoje países independentes. Alimentada quer pela esquerda mais retrógrada e quer pela direita mais nacionalista e nostálgica do império, a lusofonia deriva de uma sucessão de momentos e acontecimentos históricos.

Num primeiro momento surge a ilusão de unir o Atlântico ao Índico, Angola a Moçambique, através de um projecto político que reforçava a necessidade 
de encontrar recursos económicos extraordinários no momento em que se começavam a sentir os efeitos da revolução industrial em Portugal. Este projecto, designado como Mapa Cor-de-rosa, foi apresentado na Conferência de Berlim (1884-85) e estava altamente comprometido com a necessidade de crescimento económico do regime português. Esta proposta fundamentava-se no pressuposto de um direito de anterioridade da ocupação daqueles territórios, direito esse que, na verdade, era falso. Recorde-se que à época nenhuma potência colonial ocupava mais do que franjas do território africano. Este projeto, ainda apresentado por Portugal em 1886 e 1887 nas negociações com a França e a Alemanha foi inteiramente rejeitado pela Inglaterra que impôs o Ultimato de 1890. Note-se que, hoje, é novamente com este argumento de encontrar novos recursos, agora usando a terminologia do investimento empresarial e da cooperação económica, que se evoca a lusofonia.

Num segundo momento dá-se a apropriação salazarista da tese do lusotropicalismo desenvolvida pelo brasileiro Gilberto Freyre (1900-1987). Esta tese, que começa a ser formulada em 1933, será adotada pelo salazarismo na defesa política e diplomática do colonialismo a partir dos anos 1950 e em particular a partir de 1961.

Segundo Cláudia Castelo, "a primeira data corresponde ao ano da publicação de Casa-grande \& Senzala, obra em que são lançados os fundamentos da doutrina luso-tropicalista; a última, ao ano da publicação de $O$ Luso e o trópico, livro em que a doutrina surge em 'estado acabado'" (Castelo 1998: 34). O lusotropicalismo, que se configurou como a essência da identidade dos brasileiros, passou a ter, do outro lado do Atlântico, como objectivo, criar as bases de um império mítico construído sobre os afectos e o multirracialismo (para o qual o autor nunca vira sinais de tensão). Sem bases históricas, baseando a sua teoria na origem, também ela "mestiça", do português face à influência de judeus e árabes, na sua capacidade de adaptação aos trópicos e no seu humanismo cristão, Gilberto Freyre, sociólogo com prestígio internacional, deu à sua tese uma cientificidade que fundamentou a política do Estado Novo (a partir da segunda metade dos anos 50) e produziu, no campo cultural, um conjunto vastíssimo de miríades que acabaram por estruturar o campo das mentalidades.

Depois do 25 de Abril, muito do trauma e do luto pela perda das últimas colónias foi feito através de uma relativização da violência dos portugueses sobre os africanos: a Guerra Colonial portuguesa teria sido mais branda que as de outros países colonizadores, como se os massacres em Mihinjo (1961, Angola) e em Wiriyamu (1973, Moçambique) não fossem a expressão da barbárie. Optou-se pela imposição do que seria uma cultura comum, cuja matriz era a portuguesa, e para a qual a confusão entre língua e cultura era oportuna e baseada na relativização das dores. 
Perdido o que restava do império, a crise da identidade nacional não foi superada por um trabalho de revisão das narrativas identitárias nem por um trabalho colectivo sobre as memórias na educação, na política, nas actividades culturais e artísticas. Demorou mais de vinte anos a aparecer uma literatura Dulce Maria Cardoso, António Tavares, Isabela Figueiredo -, muito poucas artes performativas - Marlene Monteiro, Manuel Wiborg, Teatro Griot - e só a geração de cineastas que começou a filmar na década de 90 como Pedro Costa, Margarida Cardoso ou Ivo Ferreira se confrontou com as narrativas míticas e com o presente das ex-colónias. Segundo Eduardo Lourenço:

As contas a ajustar com as imagens que a nossa aventura colonizadora suscitou na consciência nacional são largas e de trama complexa demais. A urgência política só na aparência suprimiu uma questão que também na aparência o país parece não se ter posto. Mas ele existe. Querendo-o ou não, somos agora outros, embora como é natural continuemos não só a pensar-nos como os mesmos, mas até a fabricar novos mitos para assegurar uma identidade que, se persiste, mudou de forma, estrutura e consistência.

Lourenço 2007: 116

Porém, a lusofonia, no logro de ser a pátria de uma língua comum, uma forma torpe de neo-colonialismo, é também a mostra da incapacidade de construção de um país pós-colonial, de um país que não consegue olhar as suas ex-colónias numa relação de confronto de interesses e de respeito pelas identidades que cada um desses países pretende construir. Com tudo isto há, por parte da esquerda conservadora ${ }^{1}$, uma pretensa relação, baseada nos afectos e nos negócios; e, pela direita, uma relação que se baseia na nostalgia, nos negócios e na defesa do uso da língua conforme à sua matriz lusitana.

Ora, para que esta pretensão neo-colonial exista, a RTP África, a RTP Internacional e, de uma forma mais naïf, o Jornal de Letras, um jornal de perfil literário bastante conservador e apologista da lusofonia são os instrumentos adequados. Já o Acordo Ortográfico ractificado em Portugal em 2008 e que supostamente introduz as normas ortográficas em todos os países onde o português é a língua oficial, é, sobretudo pela forma como foi feito, uma tentativa de resistir ao estilhaço da lusofonia. No entanto, também não saem bem aqueles que acusam o referido Acordo de cedência da língua a outros países, como se ela fosse propriedade portuguesa. E não deixa de ser paradoxal que um governo que tanto exige da lusofonia, como se ela fosse o campo ideal de

1 Podem encontrar-se vários artigos e declarações de personalidades quer no Partido Comunista Português, quer no Partido Socialista. 
negócios - e como se alguma vez o capital tivesse um país -, desvaneça a componente cultural da missão do Instituto Camões na última Lei Orgânica de 2012 e não tenha, neste momento, nenhum conselheiro cultural em nenhum dos países africanos de língua oficial portuguesa.

Colonizar (ou neo-colonizar) e civilizar sempre estiveram juntos; por isso é recorrente encontrar, sob a forma de cooperação, a imposição de um assistencialismo em língua portuguesa que civilize sem "Ihes" perguntar (a eles) como reclama Appadurai (2001) - o que querem (o que quer o outro) e como querem (como quer esse outro) a cooperação.

Neste processo de reconstrução de identidades, o Brasil há muito começou com a investigação e a construção de narrativas das suas memórias, e até se conseguiu construir como um país de glamour e terra de oportunidades - mito que o liberta definitivamente de Portugal e o transforma numa pátria de oportunidades míticas tanto para os europeus, como para os chineses, para os antilhanos ou para os africanos. A responsabilidade desta construção mítica e aparentemente glamorosa não é, naturalmente, dos historiadores nem dos estudiosos da cultura.

Mais: em África, muitos africanos começaram também os seus trabalhos de reconstrução da identidade: de si, enquanto sujeitos históricos num dado contexto, e dos seus países. Disso são prova os trabalhos dos angolanos Ana Paula Tavares e António Tomás, do Cabo-verdiano Joaquim Arena, dos moçambicanos Mia Couto e Elísio Macamo e, em Portugal, os pertinentes estudos de Joaquim Valentim, Cláudia Castelo, ou o trabalho do Buala, um portal online dedicado à crítica e documentação de questões pós-coloniais e transatlântica, entre outros. De facto, e segundo Valentim:

se a lusofonia se mantém como um princípio organizador das representações sociais dos portugueses, não há concordância entre os portugueses e africanos a esse respeito: os portugueses valorizam-na, os africanos rejeitam-na. Dito de outro modo, a este nível, a valorização da lusofonia não encontra correspondência da parte dos africanos que são, em boa medida, interlocutores por excelência dessa lusofonia. Mais ainda, os africanos não só manifestam uma posição contrária à dos portugueses em relação à lusofonia, como a importância que atribuem à sua identidade étnico-nacional se encontra associada negativamente à valorização da dimensão lusófona nas representações das semelhanças dos portugueses com outros povos. 
É compreensível ainda que nem todos os portugueses subscrevam as teses da lusofonia, nem todos os africanos a rejeitem e no caso de Angola a não aceitação do acordo ortográfico era, paradoxalmente, em nome da defesa da língua portuguesa. E se é possível criar uma comunidade de países que têm como língua oficial o português, com todas as suas variantes, e cujo uso pelas populações como língua materna pode ir dos quase $100 \%$ (em Portugal) aos 23,5\% (em Timor) ou aos 10,7\% (em Moçambique), não é possível entender uma pátria lusófona comum a países com outras diversidades linguísticas, economias tão diferentes, regimes políticos diferentes e, em particular, histórias diferentes.

Uma das maiores violências criadas pelo luso-tropicalismo não foi querer impor ao Brasil uma essência de ser luso. Foi, embora admitindo para o Brasil a herança índia e para Portugal a herança árabe, excluir das ex-colónias africanas a sua história pré-colonial. Ora, a expressão mais perversa da lusofonia é a amnésia sobre o passado pré-colonial dos países africanos ou de Timor e, de algum modo, a repetição dessa expressão do colonialismo que foi "a descoberta" destes povos ${ }^{2}$ - que só passaram a ter história no momento em que os "descobridores" os encontraram.

A lusofonia é, pois, a última marca de um império que já não existe. É também um impedimento a um trabalho adulto sobre as múltiplas identidades de quem vive em Portugal.

Para lá dos seus contornos coloniais, a lusofonia tem o efeito de uma epistemologia negativa: impede que se entenda que a razão da criação de comunidades de países tem por base interesses políticos e económicos, bem como jogos de partilha territorial. É também assim com a francofonia, a Commonwealth, o G8 e o G20.

Foi por causa desta "realpolitik" que Lula da Silva, enquanto Presidente do Brasil, estabeleceu parcerias económicas Sul-Sul com a maioria dos países subsarianos. Para esta estratégia a lusofonia pouco importou: o argumento cultural foi a africanidade comum (outro mito, naturalmente).

Quanto aos outros países cuja língua oficial é o português, não nos resta senão admitir que produzem as suas pesquisas e trabalhos sobre as suas identidades. Se a presença dos estudos portugueses e da literatura é quase residual nas universidades de Cabo Verde, de Timor e mesmo de Angola, isso não ocorre por falta de lusofonia, mas sim por haver um excesso dessa caricatura da produção cultural portuguesa exportada que tem o nome de "Cultura Lusófona".

2 A este propósito confronte-se o recente texto de António Pinto Ribeiro (2018). 
Os portugueses não têm nenhum atributo de excepcionalidade mítica. Não precisamos de uma diplomacia lusófona; do que precisamos é de uma diplomacia de direitos e de igualdades. Este é o momento de conhecer e dar visibilidade às produções culturais e artísticas, às literaturas e aos trabalhos científicos destes países por aquilo que valem, por serem incontornáveis no mundo global, por conterem, até, uma estranheza que é, porventura, consequência da morte dessa mesma lusofonia.

\section{Bibliografia}

Appadurai, A. 2001, Après la Colonisation, Paris: Payot.

Castelo, C. 1998, O Modo português de estar no mundo, Porto: Edições Afrontamento.

Lourenço, E. 2007, O Labirinto da Saudade. Psicanálise Mítica do Destino Português, Lisboa: Gradiva.

Ribeiro, A. Pinto 2018, "O impossível museu", Memoirs. Filhos de Império e pósMemórias europeias, 18 de Maio de 2018, consultado em 30 junho 2018. http:// memoirs.ces.uc.pt/ficheiros/4_RESULTS_AND_IMPACT/4.3_NEWSLETTER/ MEMOIRS_newsletter_03_APR_pt.pdf

Valentim, J. 2003, Identidade e Lusofonia nas Representações Sociais de Portugueses e de Africanos, Coimbra: Tese de doutoramento em Psicologia Social. 